\author{
Erratum
}

Proceedings of the Workshop on mdic 2004

\title{
Multimedia Databases and Image Communication
}

This title is Vol. 17 of the World Scientific Series on Software Engineering and Knowledge Engineering. On the front cover, the volume number should be $17, \operatorname{not} 15$. 


\section{Multimedia Databases and lmage Communication}




\section{SERIES ON SOFTWARE ENGINEERING AND KNOWLEDGE ENGINEERING}

Series Editor-in-Chief

S K CHANG (University of Pittsburgh, USA)

Vol. 1 Knowledge-Based Software Development for Real-Time Distributed Systems Jeffrey J.-P. Tsai and Thomas J. Weigert (Univ. Illinois at Chicago)

Vol. 2 Advances in Software Engineering and Knowledge Engineering edited by Vincenzo Ambriola (Univ. Pisa) and Genoveffa Tortora (Univ. Salerno)

Vol. 3 The Impact of CASE Technology on Software Processes edited by Daniel E. Cooke (Univ. Texas)

Vol. 4 Software Engineering and Knowledge Engineering: Trends for the Next Decade edited by W. D. Hurley (Univ. Pittsburgh)

Vol. 5 Intelligent Image Database Systems edited by S. K. Chang (Univ. Pittsburgh), E. Jungert (Swedish Defence Res. Establishment) and G. Tortora (Univ. Salerno)

Vol. 6 Object-Oriented Software: Design and Maintenance edited by Luiz F. Capretz and Miriam A. M. Capretz (Univ. Aizu, Japan)

Vol. 7 Software Visualisation edited by $P$. Eades (Univ. Newcastle) and $K$. Zhang (Macquarie Univ.)

Vol. 8 Image Databases and Multi-Media Search edited by Arnold W. M. Smeulders (Univ. Amsterdam) and Ramesh Jain (Univ. California)

Vol. 9 Advances in Distributed Multimedia Systems edited by S. K. Chang, T. F. Znati (Univ. Pittsburgh) and S. T. Vuong (Univ. British Columbia)

Vol. 10 Hybrid Parallel Execution Model for Logic-Based Specification Languages Jeffrey J.-P. Tsai and Bing $L i$ (Univ. Illinois at Chicago)

Vol. 11 Graph Drawing and Applications for Software and Knowledge Engineers Kozo Sugiyama (Japan Adv. Inst. Science and Technology)

Vol. 12 Lecture Notes on Empirical Software Engineering edited by N. Juristo \& A. M. Moreno (Universidad Politécrica de Madrid, Spain)

Vol. 13 Data Structures and Algorithms edited by S. K. Chang (Univ. Pittsburgh, USA)

Vol. 14 Acquisition of Software Engineering Knowledge SWEEP: An Automatic Programming System Based on Genetic Programming and Cultural Algorithms edited by George S. Cowan and Robert G. Reynolds (Wayne State Univ.)

Vol. 15 Image: E-Learning, Understanding, Information Retieval and Medical Proceedings of the First international Workshop edited by S. Vitulano (Università di Cagliari, Italy)

Vol. 16 Machine Learning Applications in Software Engineering edited by Du Zhang (California State Univ.,) and Jeffrey J. P. Tsai (Univ. Illinois at Chicago)

Vol. 17 Multimedia Databases and Image Communication Proceedings of the Workshop on MDIC 2004 edited by A. F. Abate, M. Nappi \& M. Sebillo (Università di Salerno) 
Proceedings of the Workshop on $\mathbf{M d} \mathbf{i C}_{2004}$

Multimedia Databases

and Image Communication

Salerno, Italy $\quad 22$ June 2004

editors

Andrea F. Abate । Michele Nappi | Monica Sebillo

Università di Salerno, Italy

Sponsors:
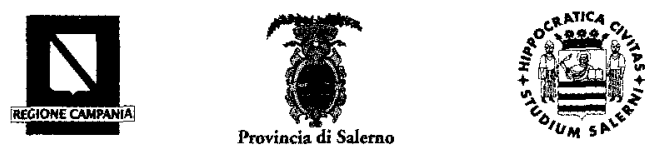

dmi

DIPARTIMENTO

DI MATEMATICA

Harand
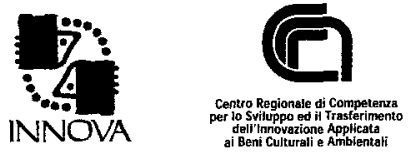

( ) mícroview 


\section{Published by}

World Scientific Publishing Co. Pte. Ltd.

5 Toh Tuck Link, Singapore 596224

USA office: 27 Warren Street, Suite 401-402, Hackensack, NJ 07601

UK office: 57 Shelton Street, Covent Garden, London WC2H 9HE

\section{British Library Cataloguing-in-Publication Data}

A catalogue record for this book is available from the British Library.

\section{MULTIMEDIA DATABASES AND IMAGE COMMUNICATION \\ Proceedings of the Workshop on MDIC 2004}

Copyright $(2004$ by World Scientific Publishing Co. Pte. Ltd.

All rights reserved. This book, or parts thereof, may not be reproduced in any form or by any means, electronic or mechanical, including photocopying, recording or any information storage and retrieval system now known or to be invented, without written permission from the Publisher.

For photocopying of material in this volume, please pay a copying fee through the Copyright Clearance Center, Inc., 222 Rosewood Drive, Danvers, MA 01923, USA. In this case permission to photocopy is not required from the publisher.

ISBN $981-256-137-4$ 


\section{PREFACE}

There is a strong need for advances in the fields of image indexing and retrieval and visual query languages for multimedia databases. Image technology is facing both classical and novel problems for the organization and filtering of increasingly large amounts of pictorial data. Novel kinds of problems, such as indexing and high-level content-based, accessing to image databases, human interaction with multimedia systems, approaches to multimedia data, biometrics, data mining, computer graphics and augmented reality, have grown into real-life issues.

The papers in this proceedings, although all related to the subject matter of multimedia databases and image communication, all have somewhat different points of view. We feel that this variety of approaches should be nurtured and commended, as it helps in keeping this field of research lively and interesting.

Finally, we would like to express our thanks to everyone who helped or otherwise cooperated to make the present proceedings volume successful: the program committee, the invited speakers, the anonymous referees, and all the researchers who have contributed with their submissions. 
This page is intentionally left blank 


\section{CONTENTS}

A Context-Aware Framework for Multimodal Document Databases

Augusto Celentano and Ombretta Gaggi

Endowing Geographic Information Systems with a

Cognitive Level

Alessio De Simone, Ferrante Formato and Nicla Palladino

A Simple Fuzzy Extension to the Search of Documents on the Web

Luidi Ďi Lascio, Enrico Fischetti, Antonio Gisolfi, Aniello Nappi and Antonio Santangelo

Developing a System for the Retrieval of Melodies from

Web Repositories

Ricardo Distasi, Luca Paolino and Giuseppe Scanniello

Fast Face Recognition Using Fractal Range/Domain Classification Daniel Riccio

A Method for 3D Face Recognition Based on Mesh Normals Stafano Ricciardi and Gabriele Sabatino

High-D Data Visualization Methods via Probabilistic Principal Surfaces for Data Mining Applications

A. Staiano, R. Tagliaferri, L. De Vinco and G. Longo

A Study on Recovering the Cloud-Top Height from Infra-Red

Video Sequences

Anna Anzalone, Francesco Isgrò and Domenico Tegolo 
viii

Powerful Tools for Data Mining: Fractals, Power Laws, SVD and More

Christos Faloutsos

An Unsupervised Shot Classification System for News Video Story Detection

M. De Santo, G. Percannella, C. Sansone and M. Vento

3D-TV - The Future of Visual Entertainment

M. Magnor

Entropy as a Feature in the Analysis and Classification of Signals Andrea Casanova and Sergio Vitulano 